\title{
Regulação ambiental no espaço urbano: a trajetória do licenciamento ambiental no município de Belo Horizonte ${ }^{1}$
}

\author{
Rogério Palhares Zschaber de Araújo* \\ Heloisa Soares de Moura Costa
}

\begin{abstract}
Resumo
Este artigo aborda as contradições e possibilidades da legislação ambiental como mecanismo de regulação de atividades urbanas, por meio da análise da trajetória dos instrumentos legais de licenciamento ambiental e dos resultados de dez anos da aplicação desse instrumento no Município de Belo Horizonte, enfatizando as mudanças associadas à definição de empreendimentos de impacto e as condições nas quais as licenças ambientais são concedidas. Finalmente, apresenta uma análise espacial com o objetivo de discutir relações entre as características e a distribuição espacial dos empreendimentos licenciados no espaço urbano.
\end{abstract}

Palavras-chave: Regulação ambiental; Espaço urbano; Política pública; Legislação; Licenciamento.

Este artigo pretende explorar a dimensão histórica da regulação ambiental no espaço urbano, a partir da análise dos dez primeiros anos de vigência do licenciamento ambiental de empreendimentos potencialmente causadores de impacto no meio ambiente e na infraestrutura urbana no Município de Belo Horizonte.

Apoiados numa perspectiva temporal e nos respectivos instrumentos legais que regulamentam e alteram as regras do licenciamento ambiental no município referido, busca-se compreender os limites e as possibilidades da regulação ambiental como instrumento de gestão de conflitos sócioambientais no espaço urbano, e averiguar como

\footnotetext{
${ }^{1}$ A análise tem origem na tese Contradições e Possibilidades da Regulação Ambiental no Espaço Urbano, apresentada ao Programa de Pós-Graduação em Geografia do IGC/UFMG em 2009, desenvolvida e orientada respectivamente pelos autores.

* Doutor em Geografia pela Universidade Federal de Minas Gerais (UFMG). Arquiteto, professor do Departamento de Urbanismo da UFMG e professor do Curso de Arquitetura e Urbanismo da PUC Minas.

** Doutora em Demografia pela Universidade Federal de Minas Gerais (UFMG); pós-doutora pelo Departamento de Geografia da Universidade da Califórnia em Berkeley. Arquiteta, professora do Programa de Pós-Graduação em Geografia (IGC/UFMG) e pesquisadora do CNPq.
} 
os objetivos de promoção da "garantia do direito a cidades sustentáveis"2 e do "cumprimento da função social da propriedade urbana", nos termos do que estabelece o Estatuto da Cidade (Lei Federal no. 10.257 de 2001, Art. 2 ${ }^{\circ}$.), trazem consigo contradições, na medida em que espaço urbano é um campo privilegiado de conflitos socioambientais, em que a regulação pode representar um importante espaço de mediação.

Fundamentados pelas contribuições teórico-conceituais da ecologia política, considera-se o meio ambiente não como uma entidade única ou como a somatória de elementos bióticos e abióticos, construídos a partir de diferentes leituras setoriais, mas como um campo de conflitos entre significados diferenciados e formas desiguais de acesso e apropriação da natureza pelos diversos grupos sociais.

Belo Horizonte representa no contexto brasileiro uma experiência precursora de implementação de um sistema municipal de licenciamento ambiental, na medida em que foi uma das primeiras cidades brasileiras a estabelecer um processo formal de licenciamento ambiental no nível municipal, que incorpora também empreendimentos imobiliários como passíveis de licenciamento (ARAÚJO, 2009). Assim, após 14 anos de aplicação desse instrumento, é importante avaliar seus impactos. A partir da sistematização e análise de dados referentes aos processos de licenciamento ambiental, procurou-se investigar a gênese e a evolução desse instrumento e trazer elementos representativos das múltiplas articulações em torno de sua aplicação, as quais podem contribuir tanto para a explicitação dos interesses em disputa quanto para a possibilidade de invisibilização de conflitos.

O artigo apresenta, inicialmente, uma breve revisão da legislação ambiental nos níveis federal e estadual, com o objetivo de contextualizar a discussão dos instrumentos legais e procedimentos administrativos de licenciamento ambiental de "empreendimentos de impacto", no Município de Belo Horizonte, analisada, cronologicamente, segundo fases distintas de sua implementação. A seguir, busca-se compreender as características distintivas dos empreendimentos licenciados e a vinculação desses com os processos de produção e organização do espaço urbano.

\footnotetext{
${ }^{2}$ Há, no âmbito da ecologia política, um amplo debate em torno do conceito de desenvolvimento sustentável e sua crítica, que transcende os limites do presente artigo. Ver por exemplo as coletâneas organizadas por Cavalcanti (1995), Peet; Watts (1996), entre outros. Há também um razoável acúmulo em torno do debate sobre cidades sustentáveis. Para uma revisão da literatura ver Costa (2000 e 2008b) e Acselrad (2001).
} 


\section{Breve Histórico da Regulação Ambiental no Brasil e no Estado de Minas Gerais}

O modelo de gestão ambiental em vigor no Brasil tem suas origens na tentativa de se integrar uma série de leis anteriores direcionadas à regulamentação de questões ambientais de caráter mais setorial, como o Código de Pesca (Decreto-Lei 794/1938), o Código Florestal (Lei Federal 4.771/1965), ou a Lei Federal 6.902/1981 relacionada à criação de Estações Ecológicas, num único arcabouço legal. A Lei Federal nº 6938/81, pretendeu cumprir essa função, ao dispor de forma integrada e abrangente sobre os fins e os mecanismos de desenvolvimento e execução da política nacional de meio ambiente. Reconhecida desde a sua promulgação como avançada e baseada em formulações conceituais adequadas do ponto de vista da dinâmica dos fenômenos ambientais, essa Lei previu medidas de prevenção e instrumentos de controle ambiental, com destaque para o licenciamento de atividades poluidoras e a exigência de Estudos de Impacto Ambiental como condição para o licenciamento prévio de atividades e projetos potencialmente prejudiciais ao meio ambiente. Instituiu o Sistema Nacional de Meio Ambiente, SISNAMA, concebido como o conjunto de órgãos e entidades da União, dos estados, do Distrito Federal, dos territórios e dos municípios, bem como das fundações responsáveis pela proteção e melhoria da qualidade ambiental.

A resolução CONAMA - Conselho Nacional do Meio Ambiente - 01/1986 regulamentou os procedimentos para o licenciamento ambiental, a partir do conceito de impacto ambiental, definido como "alterações das propriedades físicas, químicas e biológicas do meio ambiente, resultantes das atividades humanas que, direta ou indiretamente afetam a saúde, a segurança e o bem-estar da população”. Essa deliberação definiu quais empreendimentos foram então considerados previamente causadores de impacto ambiental, caracterizados principalmente por equipamentos e obras de infraestrutura de grande porte, cuja implantação provoca alterações significativas no meio ambiente natural.

A Constituição Federal de 1988 dedicou um capítulo específico ao meio ambiente (Capítulo VI do Título VIII - DA ORDEM SOCIAL), promovendo avanços no sentido do reconhecimento explícito do direito coletivo ao meio ambiente protegido e da obrigação do Estado de garantir a utilização racional dos recursos naturais, a defesa e a recomposição do meio ambiente. $\mathrm{O}$ artigo 23 reafirma ser a proteção e a preservação ambiental de competência comum da União, dos estados, do Distrito Federal e dos municípios. 
Observa-se também significativo avanço no tratamento dado ao direito privado de propriedade, que passa a estar diretamente vinculado ao cumprimento de sua função social, facilitando a adoção de instrumentos de controle do uso e da ocupação do solo e de utilização dos recursos naturais pautados por interesses coletivos. O reconhecimento explícito do direito à proteção ambiental como um direito coletivo ratificou a utilização da ação civil pública criada pela Lei Federal 7.347/85 para a defesa de interesses difusos de natureza ambiental.

Em nível federal, são marcos legais importantes: a Lei Federal 7.754/89, que altera o Código Florestal de 1965, e que, entre outros aspectos, define e classifica as Áreas de Preservação Permanentes - APPs; a Lei Federal 9.433/97, que institui a política nacional de gestão de recursos hídricos; e a Lei Federal 9985/2000 que institui o Sistema Nacional de Unidades de Conservação - SNUC.

No âmbito da legislação urbanística, importa destacar que, apesar da Lei Federal do Parcelamento Urbano (Lei 6.766/79, alterada pela Lei 9785/99) já estabelecer algumas restrições de ordem ambiental à ocupação urbana, tais como parcelamento de várzeas alagadiças e terrenos íngremes, deve-se ao Estatuto da Cidade, Lei Federal 10.259/2001, os maiores avanços no sentido de integrar conceitualmente e em termos instrumentais a questão ambiental ao desenvolvimento urbano.

Como instrumento de política urbana mais diretamente afeto à gestão ambiental do espaço urbano, o Estatuto introduz o Estudo de Impacto na Vizinhança (EIV), prévio à obtenção de licenças ou autorizações de construção, ampliação ou funcionamento de empreendimentos e atividades públicos ou privados que, por definição de Lei Municipal, sejam considerados potencialmente prejudiciais à qualidade de vida da população residente na área e em suas proximidades. O artigo 37 dessa lei definiu como aspectos relevantes a serem analisados pelo EIV, questões relativas ao adensamento populacional, aos equipamentos urbanos e comunitários, ao uso e ocupação do solo, à valorização imobiliária, à geração de tráfego e demanda por transporte coletivo, à ventilação e iluminação, à paisagem urbana e ao patrimônio natural e cultural. $O$ Estatuto estabeleceu ainda que a elaboração do EIV não substitui a elaboração e aprovação do Estudo de Impacto Ambiental (EIA), requerida pela legislação ambiental.

Contudo, como mostra Bassul (2005), tanto o dispositivo do EIV como a referência ao EIA não constavam das versões originais do Estatuto da Cidade, cujo cerne é constituído pelos princípios defendidos pelo Movimento Nacional pela Reforma Urbana, dos quais a questão ambiental esteve sempre ausente. Durante a longa e 
conflituosa tramitação do respectivo projeto de lei no Senado e na Câmara, processo que durou cerca de doze anos, foram incluídos, em 1997, o conceito de desenvolvimento sustentável e os instrumentos de gestão e controle ambientais, propostos pelo substitutivo do então deputado Fábio Feldmann. Destaca-se entre esses instrumentos o EIV, que viria perder, em 2000, parte de sua dimensão participativa antes da aprovação do texto final do Estatuto da Cidade, em 2001.

Costa (2008a), identifica, na introdução do EIV, uma tentativa de articulação de preocupações de caráter urbanístico e ambiental, cujos modelos de regulação derivam de racionalidades distintas: o primeiro, orientado pela lógica funcionalista do ordenamento do território e, mais recentemente, pela matriz da reforma urbana, o segundo, pelo binômio preservação/conservação e pela lógica da valorização econômica da natureza, presentes, entre outros, nos mecanismos de compensação e mitigação do licenciamento ambiental. Entretanto, apesar desse encontro das duas tradições de regulação ainda se dar de forma muito incipiente, conflitos importantes têm sido explicitados pelo licenciamento ambiental de empreendimentos e atividades urbanas (ARAÚJO, 2009), como discutido neste artigo. Um exemplo disso são os debates que se arrastam na Câmara Federal por mais de dez anos acerca do PL 3.057/2000, da futura Lei de Responsabilidade Territorial Urbana que, em substituição à Lei 6766/79, propõe, dentre outros mecanismos de gestão, o licenciamento urbanístico-ambiental integrado para projetos de parcelamento do solo e regularização fundiária.

A regulamentação dos dispositivos legais de proteção ao meio ambiente, em nível estadual, seguiu o referencial definido em nível federal através do SISNAMA ${ }^{3}$. Em Minas Gerais, o Sistema Estadual de Meio Ambiente - SISEMA é coordenado pela Secretaria Estadual do Meio Ambiente e do Desenvolvimento Sustentável - SEMAD, responsável pelo planejamento, execução, controle e avaliação das ações setoriais a cargo do Estado, relativas à proteção, à defesa do meio ambiente, à gestão dos recursos hídricos e à articulação das políticas de gestão dos recursos ambientais para o desenvolvimento sustentável. Conforme previsto na Deliberação Normativa 74/04 de 2004, do Conselho Estadual de Política Ambiental - COPAM, o processo de regularização ambiental pode consistir, de acordo com o porte e o potencial poluidor do empreendimento em questão, de Autorização Ambiental de Funcionamento - AAF,

\footnotetext{
${ }^{3}$ A Lei Estadual 7.772/80, alterada pela Lei 15.972/06, dispõe sobre a política estadual de meio ambiente e cria o Conselho Estadual de Política Ambiental, COPAM, que entre outras atribuições autoriza a implantação de atividade poluidora ou potencialmente poluidora mediante licenciamento ambiental.
} 
para empreendimentos classificados como Classe 1 e 2, e Licenciamento Ambiental, para aqueles classificados como Classe 3 a $6^{4}$. As atribuições do licenciamento ambiental e da Autorização Ambiental de Funcionamento são exercidas pelo COPAM, pelas Unidades Regionais Colegiadas - URCs, que são órgãos colegiados deliberativos nas esferas regionais, e pelas Superintendências Regionais de Meio Ambiente e Desenvolvimento Sustentável (SUPRAMS), órgãos técnicos que subsidiam regionalmente os processos com representação da Fundação Estadual de Meio Ambiente - FEAM, do Instituto Mineiro de Gestão das Águas - IGAM e o Instituto Estadual de Florestas - IEF. No que se refere aos procedimentos relativos a processos de regularização ambiental, as SUPRAMS subordinam-se administrativamente à SEMAD e tecnicamente à FEAM, ao IEF e ao IGAM.

Analogamente ao âmbito federal, são também relevantes do ponto de vista da regulação ambiental em Minas Gerais a Lei 13.199/1999, que define a política estadual de gestão de recursos hídricos e a Lei Estadual 14.309/2002, que define e estabelece parâmetros para as Áreas de Proteção Permanentes - APPs e Unidades de Conservação.

\section{A Trajetória da Regulação Ambiental no Município de Belo Horizonte}

A municipalização da gestão ambiental é prevista pelo SISNAMA em âmbito federal, mas depende de regulamentação específica em nível local. Nesse sentido, o crescente número de municípios brasileiros que têm incorporado princípios de sustentabilidade ambiental em seus Planos Diretores ${ }^{5}$ e adotado instrumentos de gestão e controle ambiental específicos atesta, como destaca Prestes (2005), a inserção de alguns elementos novos à pauta do planejamento e da gestão ambientais, tais como o conceito de meio ambiente e de impacto ambiental aplicado ao espaço urbano e a necessidade de integração dos instrumentos de controle urbanístico e ambiental.

A trajetória da regulação ambiental no município de Belo Horizonte pode ser melhor percebida através das seguintes fases observadas em sua implementação.

\footnotetext{
${ }^{4}$ Para a regularização ambiental, considera-se a seguinte classificação dos empreendimentos: Classe 1 pequeno porte e pequeno ou médio potencial poluidor, Classe 2 - médio porte e pequeno potencial poluído, Classe 3 - pequeno porte e grande potencial poluidor ou médio porte e médio potencial poluidor, Classe 4 - grande porte e pequeno potencial poluidor; Classe 5 - grande porte e médio potencial poluidor ou médio porte e grande potencial poluidor e Classe 6 - grande porte e grande potencial poluidor (DN $74 / 04)$.

${ }^{5}$ O tratamento da dimensão ambiental nos Planos Diretores de Municípios Brasileiros desenvolvidos pós Estatuto da Cidade foi sistematizado e analisado por Costa et al. (2011) como parte do Projeto Rede de Avaliação e Capacitação para Implementação dos Planos Diretores (convênio IPPUR/UFRJ - Ministério das Cidades).
} 


\section{Fase inicial de concepção: 1985 a 1995}

Com cerca de dez anos, foi longo o período de gestação da regulação ambiental no município de Belo Horizonte. A primeira iniciativa de controle de atividades potencialmente causadoras de degradação ambiental pelo poder executivo local foi explicitada na Lei 4.253 de, 1985, que, entre suas disposições sobre a política de proteção e conservação do meio ambiente no Município, vinculou a expedição de alvarás de localização e licença de funcionamento de fontes poluidoras a parecer técnico favorável da Secretaria Municipal de Meio Ambiente. Foi essa lei que criou o Conselho Municipal de Meio Ambiente - COMAM - como órgão colegiado composto de 15 membros representantes do poder público e da sociedade civil, com competência normativa e de assessoramento, tendo entre suas atribuições, decidir sobre o processo de licenciamento, formas de publicidade e debate público do mesmo e a aplicação de penalidades previstas.

A ausência de regulamentação dos procedimentos técnico-administrativos impediu, entretanto, durante muito tempo, que essa Lei tivesse a eficácia e a abrangência pretendida. Apesar da clara vinculação estabelecida entre a licença ambiental e a licença para construir, e outras autorizações urbanísticas que antecedem a localização e o funcionamento de atividades, o conceito de impacto ambiental subjacente ao texto ainda apresentava-se restrito à noção de degradação da qualidade ambiental causada por fontes poluidoras da atmosfera, das águas, do solo e do subsolo, restringindo os empreendimentos sujeitos a licenciamento a uma classificação subjetiva e restrita de atividades. A associação de transformações provocadas no meio ambiente urbano como um todo aos processos de urbanização, abrangendo as condições da infraestrutura bem como aspectos socioeconômicos e culturais só passaria a ser textualmente explicitada no Plano Diretor (Lei 7165/96) e na Lei de Parcelamento, Ocupação e Uso do Solo (Lei 7166/96), e de forma gradual e progressiva, nas leis, normas e decretos subsequentes, visando à regulamentação do que veio a se consolidar como um sistema municipal de licenciamento ambiental.

O Decreto Municipal 5.362/1986 aprovou o regimento interno do Conselho Municipal do Meio Ambiente e definiu os órgãos e as entidades de origem de seus membros, revelando a preocupação de se vincular a política ambiental às políticas de desenvolvimento urbano. A maioria dos assentos do COMAM foi destinada a órgãos e entidades previamente nomeados, resultando na representação de cinco membros do 
poder executivo municipal, um do legislativo, um representante do ministério público, dois representantes do setor empresarial da indústria e do comércio, três representantes do setor técnico-científico, um representante de ONG, atuante na área ambiental, um representante de associação de moradores, e um de sindicato de trabalhadores. A representação minoritária de ambientalistas e lideranças de movimentos sociais revela, desde a sua formação, o comprometimento desse Conselho com a defesa de interesses do governo e de setores hegemônicos que atuam na produção e na organização do espaço urbano, respaldados por detentores de conhecimento técnico-científico, também fortemente representados. Além disso, o caráter paritário preconizado pela legislação estadual $^{6}$, não se concretizou, considerando que o poder de voto conferido ao presidente e a indicação do representante da comunidade científica, pelo prefeito, resultaram, na representação majoritária do setor público, particularmente do executivo municipal.

Essa fase é voltada para a definição de instrumentos e parâmetros de controle ambiental, focalizando atividades com fontes flagrantes de poluição atmosférica, hídrica e sonora. O Decreto 5.893/1988 que regulamenta a Lei 4.253/85 estabeleceu, entre outros parâmetros, os níveis máximos de poluição atmosférica, sonora e hídrica permitidos para atividades instaladas no Município, e instituiu, nominalmente, o licenciamento prévio de atividades potencialmente poluidoras, atribuindo à Secretaria Municipal de Meio Ambiente a análise das informações técnicas necessárias à caracterização dos empreendimentos a serem licenciados. Definiu fontes poluidoras como sendo as atividades de comércio varejista, comércio atacadista, serviços, indústria e serviços de uso coletivo relacionados no Anexo 6 da Lei Municipal 4.034, de 1985, que dispunha, à época, sobre o uso e a ocupação do solo no Município. Essa classificação reafirma a restrição do conceito de impacto no meio ambiente urbano àqueles associados à emissão de algum tipo de poluente explicitado na legislação anterior.

A Lei Orgânica do Município de Belo Horizonte, aprovada em 21 de março de 1990, reafirma os procedimentos de gestão ambiental regulamentados anteriormente e atualiza a terminologia e os conceitos utilizados com relação ao discurso ambiental presentes nas constituições Federal (1988) e Estadual (1989). Introduz em nível local

\footnotetext{
${ }^{6}$ A Deliberação Normativa do Conselho Estadual de Política Ambiental - COPAM no 029/1998, atualizada pela DN COPAM n ${ }^{\circ} 106 / 2006$, estabelece, dentre as diretrizes para a cooperação técnica e administrativa com os órgãos municipais de meio ambiente, visando ao licenciamento e à fiscalização de atividades de impacto ambiental local, a existência de instância normativa, colegiada, consultiva e deliberativa de gestão ambiental, com representação da sociedade civil organizada paritária à do Poder Público.
} 
instrumentos até então utilizados apenas no licenciamento de empreendimentos de grande porte, regulamentados em nível federal ou estadual.

O Capítulo V, do Título VI, dessa Lei, que dispõe sobre o meio ambiente, reafirma, em seu Artigo 152, como direito fundamental introduzido pela Constituição Federal, o direito ao meio ambiente harmônico, definido como "bem de uso comum do povo e essencial à saudável qualidade de vida, impondo-se ao Poder Público e à coletividade o dever de defendê-lo, preservá-lo e manter as plenas condições de seus processos vitais para as gerações futuras". Além da menção subjacente ao conceito de sustentabilidade ambiental, explicitado pelo Relatório Brundtland, e da gestão compartilhada dos recursos naturais pelo poder público e sociedade, o referido artigo reitera a exigência do licenciamento prévio ao incumbir o Poder Público de, dentre outras atribuições, "sujeitar à prévia anuência do órgão municipal de controle da política ambiental o licenciamento para início, ampliação ou desenvolvimento de atividades e construções que possam causar degradação do meio ambiente", sendo tal licenciamento precedido da elaboração de relatório de impacto ambiental e da realização de audiência pública para informação e discussão sobre o projeto proposto.

\section{Fase de consolidação: 1996 -2001}

O período de cinco anos que se sucedeu pode ser entendido como uma fase de consolidação do Licenciamento Ambiental, seja pela regulamentação progressiva dos procedimentos e rotinas técnico-administrativas por parte do poder público, seja pela incorporação desses processos pelos empreendedores com nítidas repercussões nos custos e prazos de aprovação dos empreendimentos, ou ainda pelo aumento da quantidade de empresas de consultoria atuando nessa área.

A Lei 7.165/1996 que instituiu o Plano Diretor do Município de Belo Horizonte estabeleceu, como diretriz relativa ao meio ambiente: definir e disciplinar, através de legislação específica, as obras e atividades causadoras de impacto ambiental, em relação aos quais deverão ser adotados procedimentos especiais para efeito de licenciamento (Artigo XI da Subseção IX: Do Meio Ambiente que integra a Seção II Das Diretrizes de Intervenção Pública na Estrutura Urbana).

Concebida e aprovada em conjunto com o Plano Diretor, a Lei 7166/1996 que estabelece as normas para o parcelamento, ocupação e uso do solo urbano, revelou em sua concepção clara repercussão do pensamento ambiental em voga à época, pautada 
pelo conceito de "desenvolvimento sustentável" e de "gestão racional" dos recursos naturais como estratégia de enfrentamento da escassez. Aplicou o conceito de capacidade de suporte à infraestrutura urbana instalada como um dos fatores condicionantes dos parâmetros de ocupação, definidos segundo limites máximos de adensamento populacional para o zoneamento proposto. Também os usos foram classificados conforme a repercussão produzida no ambiente urbano: atração de veículos e pessoas, risco de segurança, geração de efluentes, ruídos e vibração. Empreendimentos de impacto foram definidos como "aqueles públicos ou privados que viessem sobrecarregar a infraestrutura urbana ou ter repercussão ambiental significativa" (Artigo $2^{\circ}$ ). A partir da aprovação dessa lei, a instalação, a construção, a ampliação ou o funcionamento dos empreendimentos de impacto ficou sujeita ao licenciamento ambiental pelo COMAM, com prévia elaboração de EIA e respectivo RIMA, "contendo análise do impacto do empreendimento na vizinhança e as medidas destinadas a minimizar as conseqüências indesejáveis e a potencializar os efeitos positivos" (Artigo 74, parágrafo $2^{\circ}$ ).

Os procedimentos para licenciamento ambiental definidos por ambas as leis foram regulamentados pela Lei Municipal 7.277/1997, que, entre outras disposições, listou os empreendimentos considerados de impacto segundo o tipo, o porte e a natureza dos impactos potenciais, e definiu a outorga de licenças ambientais pelo COMAM. Coube também ao COMAM definir, através de deliberações normativas, a regulamentação dos procedimentos técnico-administrativos para o licenciamento ambiental, incluindo o detalhamento de suas etapas e as tipologias de usos e atividades a serem licenciadas. As mais importantes, foram as Deliberações Normativas 19/1998 e 20/1999 relativas a empreendimentos em geral, e as 25, 26 e 29, todas de 1999, relativas, respectivamente, ao licenciamento de obras de infraestrutura, atividades industriais e empreendimentos de comércio e serviços.

Um convênio celebrado entre a Prefeitura de Belo Horizonte e o Governo do Estado de Minas Gerais, em 1985, atribuiu ao município a responsabilidade pelo licenciamento ambiental de qualquer empreendimento, independente do porte ou natureza da atividade. Somente nos casos de projetos localizados em áreas limítrofes com municípios vizinhos, o executivo municipal, por iniciativa própria, consulta o órgão ambiental do Estado sobre a necessidade, interesse ou conveniência de se conduzir o processo de licenciamento de forma conjunta ou apenas em nível estadual. 
Apesar de apresentar várias fragilidades do ponto de vista técnico $\mathrm{e}$ administrativo, como a ausência de critérios para enquadramento de empreendimentos, cujos impactos extrapolam os limites do município, esse convênio permanece como o único instrumento legal que regulamenta a transferência dessa função do Estado para o município de Belo Horizonte, fato que, eventualmente, segundo a natureza dos interesses em jogo, gera disputas de jurisdição pelos direitos ou obrigações relativas ao licenciamento ${ }^{7}$. De uma maneira geral, entretanto, o Estado não manifesta interesse pelos empreendimentos licenciados em Belo Horizonte, também pela natureza dos impactos, considerados mais urbanísticos, e destoantes, portanto, da tradição do licenciamento estadual, voltado para obras e equipamentos de infraestrutura, empreendimentos industriais e agrosilvopastoris, com impactos no meio ambiente natural.

Em termos processuais, a Lei 7.277/97 define que o licenciamento ambiental de empreendimentos de impacto em Belo Horizonte pode envolver até três licenças consecutivas. A licença prévia (LP) é precedida do desenvolvimento e da aprovação de EIA, e do respectivo, RIMA: e a licença de implantação (LI) de Plano de Controle Ambiental - PCA, contendo os projetos e planos executivos das medidas mitigadoras e compensatórias propostas e aprovadas pelo COMAM. E a licença de operação (LO) é concedida com base na implementação das condicionantes estabelecidas nas licenças anteriores. No caso de empreendimentos sujeitos a licenciamento, e já em funcionamento antes da entrada em vigor desta Lei previu-se a elaboração de Relatório de Controle Ambiental - RCA - em substituição ao EIA-RIMA, e do respectivo PCA, como requisitos para a obtenção de licença de operação corretiva.

Essa lei previu ainda que a outorga das licenças ambientais fosse precedida da publicação em edital, explicitando as características do empreendimento, em órgão oficial de imprensa e em jornal de grande circulação no Município, assegurado, ao público, prazo para exame do pedido, dos respectivos projetos, dos estudos ambientais, dos pareceres dos órgãos municipais e apresentação de impugnação fundamentada e por escrito. Foi definido ainda como atribuição do COMAM, promover, sempre que julgar

\footnotetext{
${ }^{7} \mathrm{O}$ licenciamento do Centro Administrativo do Governo do Estado de Minas Gerais localizado no limite norte do Município de Belo Horizonte, foi realizado do âmbito estadual, enquanto a Linha Verde que corta vários municípios da Região Metropolitana teve um de seus trechos (Bulevar Arrudas) e interseções viárias localizadas no município licenciadas pelo COMAM. Já a duplicação da rodovia MG-30, vetor de expansão metropolitana de Belo Horizonte sobre o Município de Nova Lima, licenciada pelo Estado, e o empreendimento comercial Portal Sul, licenciado em nível municipal, foram, ambos, questionados tanto por associações de bairros da zona sul como pelo Ministério Público, em função dos critérios de enquadramento e áreas de influência considerados.
} 
necessário, audiências públicas para informação sobre o projeto e seus impactos ambientais e urbanos, e discussão do Relatório de Impacto Ambiental - RIMA (Artigo $4^{\circ}$ da Lei Municipal 7.277/97). As audiências públicas devem ser realizadas na etapa de licenciamento prévio, e na área de influência direta do empreendimento, cabendo ao empreendedor a responsabilidade pela divulgação do evento que tem caráter apenas informativo.

Em 2000, a Lei 8.146 alterou a estrutura organizacional do poder executivo municipal criando secretarias de coordenação de políticas setoriais. Nessa ocasião, a então Secretaria Municipal de Meio Ambiente, depois Secretaria Municipal de Meio Ambiente e Saneamento Urbano, passou a estar subordinada à Secretaria Municipal de Coordenação de Política Urbana e Ambiental, e seu secretário passou a ocupar a presidência do COMAM. Essa nova configuração hierárquica resultou, segundo Teixeira (2004), em perda de poder político da então Secretaria de Meio Ambiente, cujo secretário também perdeu naquela ocasião a presidência do COMAM.

\section{Fase atual: a partir de 2002}

No que se refere à tentativa de se atribuir uma perspectiva histórica à evolução da regulação ambiental no espaço urbano de Belo Horizonte, entende-se que essa nova fase marcada pela explicitação dos conflitos ambientais no espaço urbano e suas contradições, foi inaugurada pela aprovação pelo COMAM da Deliberação Normativa $\mathrm{DN}-\mathrm{n}^{\circ} 42 / 2002$, que estabeleceu procedimentos administrativos diferenciados para o licenciamento ambiental de empreendimentos de impacto. Caracterizada por tensões entre controle e flexibilização, integração e compartimentação de políticas públicas urbano-ambientais, essa fase se estende até o momento atual, mas foi contemplada pela pesquisa até 2007 (ARAÙJO, 2009), abrangendo uma série histórica de dez anos do processo de licenciamento.

A partir dessa regulamentação, os processos de licenciamento foram classificados em três modalidades: integral, mediante outorga de três licenças consecutivas: LP, LI e LO; simplificado, que prescinde da etapa de LP e pode prescindir da etapa de LI em casos específicos; e corretivo, destinado aos empreendimentos que se encontravam em operação anteriormente ao advento da Lei 7.277/97, e àqueles que, uma vez convocados ao licenciamento, deverão ser submetidos à regularização ambiental para obter a LO. 
Além dessas modalidades, já havia também o licenciamento simplificado de atividades industriais consideradas de pequeno porte (menores que $1200 \mathrm{~m}^{2}$ ), independentes do potencial poluente, que conforme regulamentação específica são submetidas apenas à avaliação técnica no âmbito da Gerência de Licenciamento de Atividades Industriais a partir de instrumento declaratório fornecido pelo próprio interessado: Informações Ambientais Básicas - IAB - que suscita vistorias e parecer técnico com definição das medidas de controle e adequações cabíveis.

As etapas de licenciamento ambiental regulamentadas por essas Deliberações Normativas podem ser resumidas pelos passos representados na Figura 1, que apresenta, de forma esquemática e otimizada, os fluxos de tramitação de processos de licenciamento ambiental na modalidade integral (LP, LI e LO) no Município.

Ao longo do período analisado pela pesquisa, mais de sessenta deliberações normativas foram aprovadas, muitas delas destinadas à regulamentação de procedimentos especiais para o licenciamento de atividades específicas através de procedimentos simplificados no âmbito de Câmaras Especializadas, compostas de técnicos do executivo e membros do COMAM, criadas especificamente para esse fim, eliminando-se a necessidade de aprovação pelo plenário do Conselho ${ }^{8}$. Outras deliberações também dispõem sobre simplificações do processo de licenciamento, porém no âmbito do próprio COMAM. Dois exemplos merecem destaque: a DN n. ${ }^{\circ}$ $53 / 2004$, que estabelece procedimentos especiais para empreendimentos de interesse social, como resultado de pressões de grupos internos do executivo municipal e movimentos sociais ligados à luta pela moradia, no sentido de reduzir custos e burocracia em torno dos projetos de habitação social, e a DN n. ${ }^{\circ} 63 / 2008$, que aumenta o limite de porte para empreendimentos imobiliários sujeitos a licença prévia.

Resultados de articulações diversas, esses exemplos ilustram de um lado a relativa flexibilidade conferida ao licenciamento ambiental através do mecanismo das deliberações normativas, adaptando-se a interesses múltiplos representados no Conselho interessados em conferir, por exemplo, maior previsibilidade, agilidade e menor exposição pública aos processos de licenciamento. Por outro lado, é fala recorrente dos entrevistados $^{9}$ de que o COMAM tornou-se um braço do executivo, um órgão licenciador, com pouca ou nenhuma discussão de políticas ambientais. A natureza das

\footnotetext{
${ }^{8}$ São exemplos a DN n. ${ }^{\circ}$ 35/2001 sobre licenciamento das antenas de telecomunicações, a DN 43/2002, referente à realização de eventos de grande porte em espaços públicos (paradas, shows etc.), e a DN $61 / 2008$, referente aos postos de gasolina.

${ }^{9}$ Ver Araújo (2009) para um detalhamento das entrevistas realizadas.
} 
DNs, regulamentando predominantemente procedimentos administrativos do licenciamento, atesta essa percepção. Outra observação comum feita por representantes de diversos setores refere-se à necessidade de simplificar procedimentos burocráticos e reduzir os prazos do licenciamento. 
Figura 1: Fluxo dos Procedimentos de Licenciamento Ambiental no Município de Belo Horizonte, Modalidade Integral

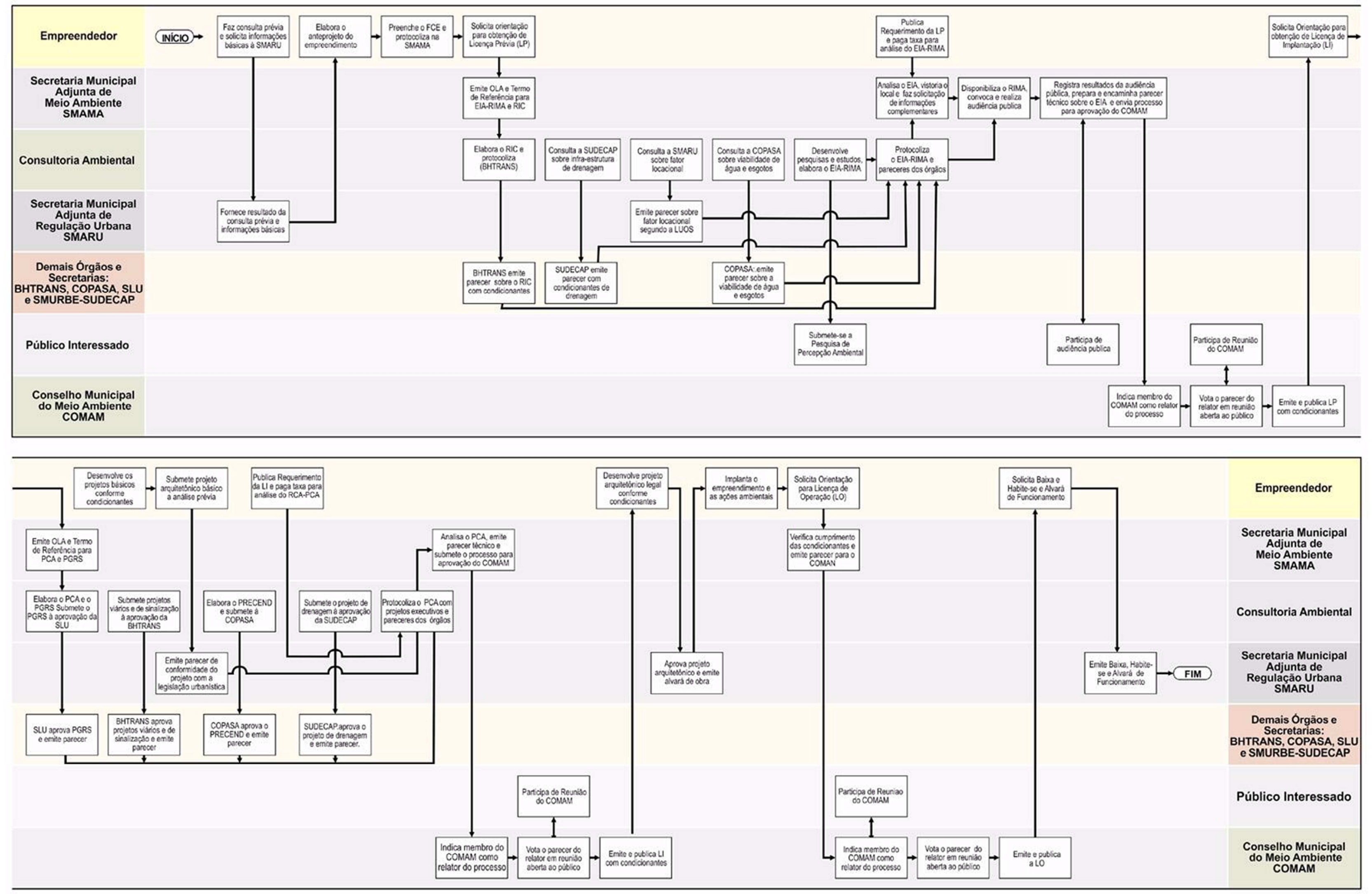

Fonte: (ARAÚJO, 2009, p.70) 
Caracteriza também essa fase conflituosa da regulação ambiental em Belo Horizonte, acirrada disputa pelas representações e pela presidência do COMAM, atestando seu grau de consolidação e reconhecimento de seu poder como influente instancia deliberativa no âmbito do planejamento e da gestão urbano-ambiental do Município. Em 2005, a Lei 9.011 que alterou a estrutura administrativa da Prefeitura Municipal reiterou a vinculação das políticas urbanas e ambientais, com a Secretaria Municipal Adjunta de Meio Ambiente - SMAMA, subordinada à Secretaria Municipal de Políticas Urbanas - SMURBE, cujo secretário permaneceu como presidente do COMAM. Em 2009, a pasta do meio ambiente sai do guarda chuva das políticas urbanas e volta a ser uma secretaria ligada diretamente ao prefeito através da Lei Municipal 9.718 numa clara prevalência das disputas internas de poder sobre a integração natural das políticas urbanas e ambientais. Esse arranjo institucional que abriga separadamente as políticas ambientais e urbanas prevaleceu na última reforma administrativa implementada pela Lei Municipal 10.101/2011 que criou a Secretaria Municipal de Desenvolvimento à qual se vincula a Secretaria Municipal Adjunta de Planejamento Urbano, responsável pela implementação do EIV.

Também durante essa fase tem-se o Decreto 11944/2005, depois modificado pelo Decreto 12012/2005 que, ao alterar o Decreto 5362/86, inverteu a representação majoritária no COMAM dos membros do poder público e da sociedade civil em favor dos últimos, revogando-se, entretanto, a especificação das entidades a serem representadas e a forma de indicação dos representantes, que deixou de ser direta pelas próprias entidades e homologada pelo próprio Conselho e, passou a ser por nomeação do Prefeito Municipal. Dessa forma, a autonomia do COMAM foi reduzida, ficando sua atuação mais sujeita a articulações prévias do executivo municipal. Sobre matéria análoga, os trabalhos de Carneiro (2005) e Zhouri et al (2005), relativos às práticas de licenciamento ambiental no âmbito do Estado de Minas Gerais, apresentam contundente questionamento do caráter "democrático" e "participativo" do Conselho Estadual de Política Ambiental - COPAM associado à sua progressiva oligarquização, insuficiência de participação das populações atingidas por impactos ambientais e concentração de atribuições e poder por parte do executivo.

Questões semelhantes, envolvendo as transformações da composição do COMAM e seus reflexos em termos da legitimidade de suas deliberações, são frequentemente associadas ao evidente desequilíbrio numérico entre as representações de setores técnico-profissionais e empresariais, de um lado, e associações de bairro, 
movimentos sociais e ambientalistas de outro, em favor dos primeiros. Observa-se também que há pouca renovação no Conselho, com grande rotatividade de seus membros por diferentes entidades, sob a mesma categoria genérica de "sociedade civil"10. Contribui também para os questionamentos sobre a representatividade do COMAM, a crescente presença do poder executivo municipal, ocupando inclusive assentos originalmente reservados à sociedade civil através de fundações municipais de meio ambiente.

\section{Análise Geral dos Empreendimentos Licenciados}

A análise de dados empíricos relativos ao período de vigência do licenciamento ambiental em Belo Horizonte (1997-2007), sintetizada a seguir, buscou captar as principais características dos 479 empreendimentos submetidos à apreciação do COMAM. Foram excluídos da análise atividades e empreendimentos licenciados por procedimentos administrativos simplificados no âmbito das gerências e câmaras técnicas, portanto, não submetidos ao COMAM. Além dos empreendimentos de impacto, integram também o universo pesquisado, os programas e projetos urbanísticos setoriais, os projetos de parcelamento e autorizações para intervenção em áreas de interesse ambiental, e os projetos que têm que ser submetidos a licenciamento através do COMAM.

Esse conjunto de empreendimentos foi analisado segundo o tipo de uso ou atividade, o público alvo segundo renda (no caso de empreendimento residencial), o porte, o potencial poluente (no caso do uso industrial), a natureza e a abrangência dos impactos, buscando relacioná-los com a lógica da estruturação do espaço urbano municipal e metropolitano.

A Tabela 1 mostra a frequência dos empreendimentos submetidos a licenciamento ambiental no período estudado.

\footnotetext{
${ }^{10} \mathrm{Um}$ mesmo conselheiro permanece, por exempli, por sucessivas gestões, representando, ora entidade técnico-profissional, ora o setor acadêmico ou a assessoria técnica a movimentos sociais.
} 
Tabela 1 - Empreendimentos submetidos a licenciamento ambiental no COMAM (1997-2007)

\begin{tabular}{|c|c|c|}
\hline \hline \multicolumn{1}{|c|}{ Tipo de Uso } & Absoluto & Relativo (\%) \\
\hline Industriais (total) & 68 & 14 \\
\hline Potencialmente poluentes & 34 & 50,0 \\
\hline Não poluentes & 34 & 50,0 \\
\hline Residenciaise Misto (total) & 94 & 20 \\
\hline Alta / Média Renda & 69 & 73,4 \\
\hline Interesse Social & 25 & 26,6 \\
\hline Infra-estrutura (total) & 77 & 16 \\
\hline Urbana & 70 & 90,9 \\
\hline Planos de Infra-estrutura e urbanização & 7 & 9,1 \\
\hline Comércioe Serviços (total) & $\mathbf{2 0 7}$ & $\mathbf{4 3 , 2}$ \\
\hline Equipamentos de Mercado & 127 & 61,4 \\
\hline Equipamentos de Uso Coletivo & 80 & 38,6 \\
\hline Autorizações para Intervenção em ADE Ambiental & $\mathbf{2 7}$ & 5,6 \\
\hline Autorização para supressão de vegetação arbórea. & 11 & 40,7 \\
\hline Recuperação de área degradada & 13 & 48,1 \\
\hline Lutros & 3 & 11,2 \\
\hline Licença para realização de evento & 4 & $\mathbf{0 , 8}$ \\
\hline Licença para extração mineral & 4 & 100 \\
\hline \hline
\end{tabular}

Fonte: Secretária Municipal Adjunta de Meio Ambiente de Belo Horizonte, 2007; ARAÚJO, 2009.

No que se refere ao tipo de uso, a maioria dos empreendimentos pertence ao setor de comércio e serviços, perfazendo cerca de $43 \%$ dos processos, seguidos daqueles residenciais que representam $20 \%$ do total, confirmando a natureza da base econômica do Município de Belo Horizonte com sua maior representação no setor terciário e importante atividade imobiliária no segmento residencial, com destaque para empreendimentos voltados para as populações de alta e média renda (mais de $73 \%$ dos empreendimentos residenciais). Em seguida, representando cerca de 16\%, destacam-se as obras de infraestrutura urbana, seguidas dos empreendimentos industriais com igual distribuição de frequência entre aqueles não poluentes e potencialmente poluentes. Com relação a essa categoria de uso, vale lembrar que apenas empreendimentos industriais de grande porte (com área construída superior a $1.200 \mathrm{~m}^{2}$ ) são licenciados pelo Conselho. Considerando que potencial poluente não tem relação direta com o porte do estabelecimento, os dados disponíveis mascaram, em alguma medida, a análise no que se refere à atividade industrial.

A atividade minerária, embora significativa na Região Metropolitana, é pouco expressiva no Município, o que é refletido no pequeno número de empreendimentos 
desse setor submetidos ao licenciamento (2), representando apenas $0,4 \%$ do total. Também com menos de $1 \%$ do total dos processos, figuram as licenças para realização de eventos de impacto $(0,8 \%)$, lembrando que essa categoria de uso deixou de ser licenciada a partir de 2002. Os demais processos, agrupados na categoria "outros", referem-se principalmente a autorização para supressão de cobertura vegetal, intervenções em áreas de interesse ambiental e recuperação de áreas degradadas (5,6\%).

A distribuição espacial dos empreendimentos licenciados pelo COMAM por tipo de uso ilustrada pela Figura 2, revela forte relação com a organização do espaço intraurbano segundo a lógica excludente de estruturação do espaço metropolitano e da atuação do mercado imobiliário, com maiores investimentos concentrados nas regiões centrais e pericentrais com destaque para região Centro Sul, com empreendimentos de comércio e serviços ao longo das principais vias arteriais, indústrias poluentes e empreendimentos residenciais de interesse social em áreas mais periféricas.

A crescente especialização da base econômica municipal em atividades de comércio e serviços e o esgotamento de áreas livres para expansão urbana dentro do território municipal foi evidenciada pela progressiva migração de atividades industriais poluentes e de outros usos indesejáveis de Belo Horizonte para municípios vizinhos na Região Metropolitana, como clara manifestação de um ciclo vicioso de injustiça socioambiental (ACSELRAD, 2003), já que muitos desses municípios concentram parcelas significativas dos segmentos de baixa renda que para lá se dirigiram a partir dos conhecidos processos de produção da precariedade socioambiental das periferias metropolitanas. Também contribuem para essa migração a fragilidade políticoinstitucional de governos locais periféricos que adotam políticas permissivas para atração de atividades econômicas para seus municípios, mesmo que para isso tenham que arcar com elevados custos ambientais.

O acirramento das pressões pela flexibilização das condições de uso de áreas de proteção ambiental ficou evidente pelo significativo número de autorizações para intervenções em "áreas de diretrizes especiais ambientais" (ADE ambiental cf. tabela 1), enquanto bairros de alta renda permanecem "protegidos" da localização de empreendimentos impactantes.

A distribuição espacial dos empreendimentos licenciados por porte, tipo de uso, potencial poluente e público alvo confirmam essas observações, mostrando que o licenciamento ambiental não altera e sim reforça a ordem mercadológica de estruturação do espaço urbano. A lógica de mercado na distribuição espacial dos usos transparece 
também na legislação urbanística quando ela atribui maiores coeficientes de aproveitamento para áreas mais bem dotadas de infraestrutura urbana, segundo princípios já mencionados de capacidade de suporte que tendem a reproduzir essas relações. Nesse sentido, investimentos públicos na macro infraestrutura urbana, são fortemente influenciados por interesses de mercado, contribuindo para a valorização fundiária e imobiliária diferenciada dos espaços na cidade. Os investimentos públicos em infraestrutura viária na direção norte, na chamada Linha Verde, constituem um exemplo recente de convergência de interesses entre investimento público e capital imobiliário, aumentando a rentabilidade dos investimentos privados que se anunciam na região e penalizando comunidades mais pobres e estratos sociais menos articulados com tais interesses dominantes. Os casos de remoções compulsórias e o aumento já detectado de preços de imóveis na região são importantes exemplos de injustiça socioambiental e potenciais deflagradores de conflitos.

Cabe observar que a classificação das Zonas de Proteção - ZPs - serve também à manutenção de áreas com ocupação exclusivamente residencial unifamiliar ${ }^{11}$, correspondentes a bairros predominantemente destinados a população de alta renda, como Mangabeiras e Santa Lúcia na zona sul e São Luiz e Bandeirantes na região da Pampulha, dessa forma "protegidos" da instalação de empreendimentos de impacto. O esgotamento de áreas de expansão urbana, no Município, e a proliferação da tipologia de condomínios fechados verticais ${ }^{12}$, a exemplo do processo de verticalização ocorrido nos bairros Buritis e Belvedere III, têm resultado, entretanto, em pressões para a flexibilização do zoneamento naqueles bairros, em que predomina a ocupação residencial unifamiliar (ZP 1 e ZP 2), e para ocupação de áreas protegidas por restrições ambientais. Os recorrentes debates referentes à em torno da ocupação do entorno da Lagoa da Pampulha ou à polêmica recente, envolvendo projetos imobiliários localizados na região das cabeceiras do Córrego Acaba Mundo, no extremo sul do município de Belo Horizonte, exemplificam novas formas de conflitos socioambientais que se tornam visíveis durante o processo de licenciamento ambiental.

\footnotetext{
${ }^{11}$ Trata-se de terminologia usual na legislação urbanística, para designar a ocupação de um lote por uma única unidade familiar, em oposição a ocupação multifamiliar, que pressupõe várias unidades familiares no mesmo lote, a exemplo de edifícios de apartamentos.

12 Condomínios fechados verticais são versões mais complexas de prédios de apartamentos, que incorporam áreas de lazer, serviços e equipamentos coletivos - churrasqueiras, salas de ginástica, saunas, etc - muitas vezes localizados em áreas verdes e de preservação internas ao empreendimento. Trata-se de uma forma de apropriação privada e mercantil da natureza, que se materializa na forma de renda diferencial e agregando valor ao empreendimento (COSTA, 2006).
} 
Como resultado, chama atenção o número significativo de projetos de conjuntos residenciais de grande porte, que são considerados pela legislação como empreendimentos de impacto, logo, passíveis de licenciamento e objetos dessa análise. Orientados para alta e média renda concentram-se em áreas que vêm sofrendo um processo de substituição de casas unifamiliares e edifícios de pequeno porte por torres residenciais, comerciais e de uso misto na Zona Central (bairros de Lourdes e Funcionários) e de novas frentes de expansão e adensamento na Zona Sul e Região Oeste (Belvedere, Santa Lúcia e Buritis), e Zona Norte, na Região da Pampulha (bairros Castelo e Aeroporto). Constituídos por condomínios fechados verticais, esses empreendimentos caracterizam-se por altas densidades e provisão de áreas de lazer de uso comum com forte apelo às condições de segurança privada, e do que é seguidamente denominado como qualidade de vida associada a algum atributo ambiental como parte integrante de sua estratégia comercial. Tais empreendimentos trazem para o interior dos espaços privados muitas das atividades que, na cidade convencional, são típicas do espaço público.

Já os empreendimentos residenciais de interesse social, sejam eles de iniciativa pública ou privada, localizam-se todos em áreas periféricas. Em contraposição à tendência observada nos empreendimentos residenciais privados, a prevalência de tipologias de pequeno porte nos empreendimentos de interesse social traduz a política municipal de produção habitacional que tem privilegiado a implantação de pequenos conjuntos habitacionais em lotes já urbanizados. Segundo os parâmetros legais, tendo em vista o porte e o número de unidades habitacionais, tais empreendimentos não são considerados pela legislação como de impacto ${ }^{6}$, prescindindo, portanto, de passarem por processo de licenciamento. É interessante notar que os empreendimentos residenciais de interesse social atuais, a exemplo daqueles vinculados ao Programa Minha Casa, Minha Vida, apesar de serem usualmente de grande porte, usufruem de modalidades mais simplificadas de licenciamento, como previsto na legislação federal que instituiu o Programa. Trata-se de uma postura mais permissiva que facilita e agiliza a implantação dos empreendimentos, colocando-os para além dos mecanismos de controle urbanístico e ambiental em vigor, com consequências ainda por serem avaliadas.

\footnotetext{
${ }^{6}$ São considerados de impacto, empreendimentos com 150 ou mais unidades habitacionais e com área igual ou superior a $6000 \mathrm{~m}^{2}$ de área construída. Tais parâmetros viriam a se alterar em 2010, portanto fora do horizonte temporal de nossa análise.
} 
A categoria infraestrutura urbana mostra uma distribuição espacial um pouco mais equilibrada pelo conjunto das regiões, ainda que com maior concentração, na região Centro Sul, e ausência de empreendimentos nas porções periféricas das regiões Norte e Nordeste e na porção sul da região do Barreiro. São áreas ainda desarticuladas do restante do território municipal, caracterizadas pela precariedade das redes de infraestrutura e concentração de população de baixa renda, além da presença de zonas de preservação ambiental - ZPAMs - bem como as chamadas Áreas de Diretrizes Especiais - ADEs - Ambientais, a exemplo das bacias do Córrego Bonsucesso, na região do Barreiro, e do Córrego Isidoro, no limite nordeste do município.

A distribuição dos empreendimentos licenciados, segundo o porte, mostra maior concentração dos empreendimentos de médio e grande porte na Região Centro Sul e ao longo do sistema viário arterial traduzindo a lógica da Lei de Uso e Ocupação do Solo do Município, que incentiva a localização de empreendimentos de maior impacto à maior capacidade operacional do sistema viário. O cruzamento das variáveis porte e uso não revelou nenhuma característica inesperada; 50\% dos empreendimentos licenciados são de grande porte, seguidos daqueles classificados como de médio (37\%), e pequeno porte $(13 \%)$.

Ainda que não seja significativa a presença do uso industrial no município, atividade concentrada principalmente nos municípios de Betim e Contagem, na Região Metropolitana, os dados apresentados não permitem uma análise mais aprofundada sobre a distribuição de atividades industriais, eventualmente poluentes, uma vez que, por serem de pequeno porte, não são classificadas pela legislação como empreendimentos de impacto. 
Figura 2: Empreendimentos submetidos a licenciamento ambiental pelo COMAM, por tipo de uso (1997-2007)

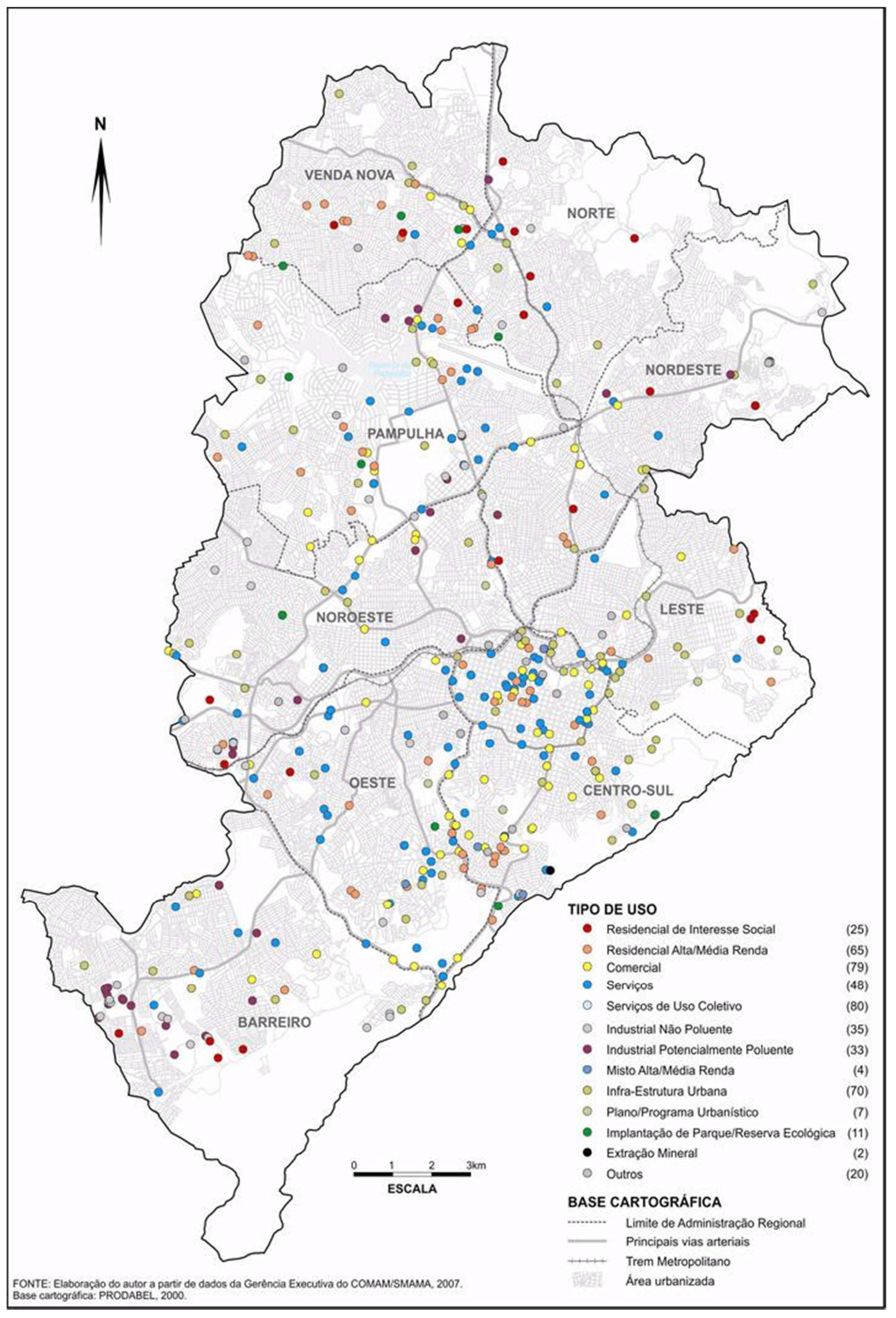

Fonte: (ARAÚJO, 2009). 
No que se refere à natureza do empreendimento, $79 \%$ dos casos pesquisados são privados, $20 \%$ públicos e apenas $1 \%$ resultaram de parcerias público-privadas. No que se refere à distribuição espacial, observa-se uma maior concentração dos empreendimentos privados nas regiões de maior atuação do mercado imobiliário formal, a exemplo dos bairros da Região Centro Sul; e uma maior dispersão dos empreendimentos públicos pelas diversas regiões, com incidências localizadas também em áreas de ocupação informal, correspondentes a intervenções de saneamento e urbanização de favelas, a exemplo de projetos em bacias de detenção nos Córregos Vilarinho e Jatobá, e intervenções no Aglomerado da Serra. Os empreendimentos, em parceria, correspondem a obras e equipamentos de infraestrutura como terminais de transporte coletivo (e.g. Estação do BH-Bus Barreiro e Vilarinho) e melhorias viárias. Essas últimas constituem um caso interessante, pois surgem como medidas mitigadoras de impacto no trânsito oriundas de empreendimentos em licenciamento e terminam por serem, elas próprias, também objeto de licenciamento, como ocorreu no caso da construção da trincheira de retorno na BR-356, surgida como medida mitigadora da implantação do Hipermercado Extra às margens da rodovia.

Quanto às modalidades de licenciamento ambiental, a maioria dos processos corresponde a licenciamentos corretivos $(31,7 \%)$, seguidos dos simplificados $(27,4 \%)$. Apenas 23,6\% do total de empreendimentos foram submetidos a licenciamento integral, em três etapas. Em dez anos, apenas 21 licenças foram indeferidas ou cassadas, sendo a maioria delas (14 ou 66,7\%) correspondentes a Licenças de Operação - LO, última fase do processo de licenciamento, no qual as medidas solicitadas tendem a ter caráter corretivo e o empreendimento já se encontra implantado e, em alguns casos, em funcionamento. Esses dados confirmam o caráter adaptativo do licenciamento ambiental que, através de medidas de controle, mitigação e compensação ambiental, contribuem mais para a adequação das atividades e sua modernização ecológica do que para a deliberação sobre sua viabilidade locacional e ambiental (HARVEY, 1996).

A predominância crescente da modalidade simplificada, por força de sucessivas deliberações, contribui para a frustração do papel idealizado para o licenciamento ambiental, no que se refere à avaliação prévia da viabilidade dos empreendimentos, e ao possível condicionamento de sua concepção pela adoção de dispositivos de controle ambiental e inovações tecnológicas, funções essas previstas originalmente para a etapa de LP. Esse papel do licenciamento ambiental como instrumento de promoção da chamada modernização ecológica é pouco relevante, também, pelo reduzido número de 
empreendimentos submetidos a esse tipo de processo. Como se vê, no período estudado, ou seja, ao longo de dez anos, apenas 479 empreendimentos foram submetidos à apreciação do COMAM. A título de comparação cabe ressaltar que o número de projetos urbanísticos e arquitetônicos aprovados anualmente na Secretaria Municipal de Regulação Urbana gira em torno de 1000, média que vem crescendo nos últimos anos em função principalmente do aumento da atividade de construção civil no Município.

Quanto aos eventos participativos vinculados aos processos de licenciamento, foram realizadas 137 reuniões deliberativas do COMAM abertas ao público e 31 audiências públicas, essas últimas correspondendo a apenas 6,5\% do total de processos de licenciamento. Considerando-se que no mesmo período de dez anos foram licenciados 98 empreendimentos públicos, nem mesmo planos e obras de infraestrutura e urbanização, cuja discussão é, em tese, mais diretamente associada aos interesses das comunidades, foram sempre objeto de consulta popular. Ainda assim, o percentual de empreendimentos de iniciativa pública submetidos a audiência pública (12\%) é bem superior àqueles de iniciativa privada (5\%).

O caráter público do licenciamento é reconhecido como um de seus principais méritos, com diferentes conotações e valores dados à consulta pública e à participação. As entrevistas realizadas com agentes sociais, provenientes dos diversos segmentos que participam do processo de licenciamento, revelam uma percepção generalizada de que o processo de participação, da forma como tem ocorrido, é claramente insuficiente.

Apesar da realização de audiências públicas ser prevista em lei como resultado de solicitação de qualquer parte interessada, a maioria não foi convocada pelos representantes da sociedade civil, mas sim pelo poder executivo municipal. Entrevistas com agentes públicos envolvidos com os processos de licenciamento apontam que o poder público tende a se antecipar e convocar audiência pública em função da percepção de conflitos de interesse detectados durante o processo de licenciamento. Tal atitude representa uma tentativa de controle da participação no momento da audiência ${ }^{14}$.

\section{Considerações finais}

Constata-se, inicialmente, que a trajetória da regulação ambiental, relativa ao licenciamento de atividades potencialmente causadoras de impactos ambientais, parece

\footnotetext{
${ }^{14}$ Ver Araújo (2009) para uma análise detalhada das audiências públicas de empreendimentos polêmicos.
} 
seguir a trajetória da regulação ambiental brasileira como identificada por Viola e Leis (1992), com valores e propostas que progressivamente se disseminam por estruturas governamentais, organizações não governamentais, grupos comunitários de base, comunidade científica e empresariado, traduzidos tanto nos instrumentos utilizados pelos processos de licenciamento como na composição dos órgãos colegiados responsáveis pela formulação das políticas ambientais e autorização das licenças.

Entretanto, segundo esses autores, a importância discursiva da questão ambiental traduziu-se numa legislação comparativamente avançada, porém com comportamentos sociais e individuais muito aquém desse mesmo discurso. Fernandes (1992) argumenta na mesma direção, ao reconhecer a grande contradição existente entre o arcabouço legal existente no Brasil para a proteção do meio ambiente, considerado por ele adequado e satisfatório, e a gravidade da situação de degradação ambiental no campo e nas cidades, associada às dificuldades para a incorporação da participação dos cidadãos na gestão do meio ambiente.

Carneiro (2005) identifica defasagem semelhante entre, de um lado, o arcabouço legal e o modelo de gestão ambiental em vigor no Estado de Minas Gerais e, de outro, as práticas desastrosas nos processos de licenciamento ambiental e na atuação do COPAM. O autor analisa o caso da constituição da APA-Sul, na Região Metropolitana de Belo Horizonte, dentre outros, para exemplificar como tais práticas se caracterizam por um alto grau de prevalência de interesses corporativos e do poder executivo em detrimento de interesses de comunidades tradicionais atingidas por grandes empreendimentos, particularmente os minerários, no caso em questão.

Em nível local, o caso de Belo Horizonte é exemplar para ilustrar fenômeno semelhante de progressiva incorporação do discurso ambiental pela legislação urbanística e a crescente evolução da regulação ambiental na direção da municipalização e da sofisticação dos procedimentos de controle ambiental, bem como da integração desses com outros instrumentos de gestão urbanística ${ }^{15}$.

Do ponto de vista dos instrumentos de participação democrática, a consolidação do COMAM como um fórum aberto de discussão das questões ambientais da cidade, dentro dos limites da representação dos conselheiros ${ }^{16}$, denota avanços, ainda que

\footnotetext{
${ }^{15}$ Sobre as inovações introduzidas na concepção da legislação urbanística de Belo Horizonte, ver Mol (2004) e Freitas (1996).

16 Ver Araújo (2009), especialmente capítulo 5, para uma avaliação crítica da representação dos conselheiros no COMAM. Já Carneiro (2005) apresenta análise semelhante para o COPAM no nível estadual.
} 
tímidos, no sentido da politização desse debate, a partir da explicitação das formas diferenciadas de apropriação dos recursos naturais e distribuição dos ônus da urbanização.

Por outro lado, a burocratização do processo de licenciamento e sua progressiva subordinação ao controle do executivo municipal apontam para o papel ambíguo do Estado que oscila entre a adoção de práticas participativas e frequentes tentativas de controle do processo. Observa-se também a prevalência de soluções adaptativas na direção da modernização ecológica, em detrimento do questionamento da implantação da própria atividade. Em um nível mais amplo, o processo de licenciamento não propicia o questionamento dos modelos de desenvolvimento urbano em vigor ou a busca de alternativas que atendam a uma maior diversidade de atores e demandas sociais.

Em contrapartida, o licenciamento ambiental em nível local vem se consolidando, no caso brasileiro, como uma tentativa de integração da regulação ambiental, de forte tradição preservacionista, com a regulação urbanística, de origem positivista $^{17}$, que, tendo incorporado mais recentemente o ideário da reforma urbana, procura, em princípio, fundir os princípios de sustentabilidade, função social da propriedade e gestão democrática das cidades, tal como explicitado, por exemplo, no Estatuto da Cidade. Dessa forma, a regulação ambiental no espaço urbano acaba por explicitar os conflitos e as contradições existentes entre essas duas vertentes de políticas públicas oriundas de racionalidades distintas. A esse respeito, identifica-se, no caso estudado, uma clara manifestação da ambição conciliadora, e contraditória, dos objetivos de uma legislação urbanística em grande medida moldada pelos interesses do mercado imobiliário, com os ideais de sustentabilidade ambiental ou de um determinado tipo de visão de política ambiental, ora apoiada na lógica da preservação, ora apoiada na lógica da valorização econômica da natureza. A regulação urbanística muitas vezes se apoia na metodologia do processo de licenciamento e no discurso ambiental para enquadrar os empreendimentos licenciados, sem, contudo, impedir sua aprovação, ratificando, portanto, os interesses dos capitais que os geraram. Por sua vez, a regulação ambiental, ao se prender a critérios que definem os empreendimentos passíveis de

\footnotetext{
${ }^{17}$ Ou seja, uma legislação que persegue objetivos de legitimação de uma determinada ordem urbanística, que visava adequar a cidade aos imperativos do nascente capitalismo industrial e considerava a natureza como recurso a ser apropriado pela sociedade em nome de um progresso técnico e instrumental. Para uma distinção entre as origens diferenciadas da regulação urbanística e da regulação ambiental, ver Costa (2008a).
} 
licenciamento, bem como a conceituação de área de influência dos empreendimentos, dificilmente consegue avaliar seus impactos sobre a estrutura urbana de forma mais ampla.

Contudo, os resultados dos processos de licenciamento estudados evidenciaram avanços no sentido da integração de políticas setoriais e da explicitação de conflitos tanto pelo seu caráter discricionário quanto pela maior transparência e flexibilidade dos mecanismos de participação previstos, em comparação ao ato administrativo estatutário de concessão de alvarás de construção e funcionamento de atividades (ARAÚJO, 2009). Ainda que o licenciamento ambiental, em Belo Horizonte, tenha impacto limitado em função da reduzida proporção de empreendimentos submetidos a essa modalidade de aprovação no contexto geral de produção do ambiente construído, e diante da significativa participação do mercado informal ${ }^{18}$, seus resultados mostram que ele exerce papel importante na consolidação do discurso ambiental hegemônico.

Outra consequência, evidenciada pela pesquisa empírica associada à crescente sofisticação dos procedimentos de licenciamento ambiental, refere-se à "reputação" a ele atribuída como um processo caro, mas, principalmente, demorado, penalizando tanto empreendedores quanto a máquina estatal com procedimentos burocráticos sofisticados e produção de muita informação que não é, sequer, sistematizada. Essas razões, entre outras, explicam as tentativas observadas de "fuga" do enquadramento legal por parte de atividades que se deslocam para outros municípios menos rigorosos. Explicam ainda as constantes pressões de agentes públicos e privados no sentido da simplificação e flexibilização dos procedimentos do licenciamento ambiental.

Contudo, um dos principais méritos constatados na prática de licenciamento ambiental refere-se à busca de uma análise integrada de diferentes impactos tanto do campo urbanístico como do campo ambiental no espaço urbano. Nesse sentido, entendese como retrocesso, as recentes modificações introduzidas pela Lei Municipal 9952/2010, que instituiu a separação entre os dois processos de licenciamento: essa lei redefine os empreendimentos e as atividades que passam a ser submetidos de forma excludente ao licenciamento urbanístico, através de EIV, sob a responsabilidade da Secretaria Municipal de Desenvolvimento Urbano e do Conselho Municipal de Política

\footnotetext{
${ }^{18}$ Estudos realizados por nós no âmbito dos Planos Diretores Regionais, em Belo Horizonte, estimam que cerca de $70 \%$ das edificações construídas no município não passam inicialmente por qualquer processo de licenciamento ou aprovação formal. Estudos semelhantes feitos pelo Plambel, na década de 1970, estimavam que $67 \%$ das edificações eram fruto da iniciativa do próprio usuário.
} 
Urbana - COMPUR, e aqueles que devem ser submetidos ao licenciamento ambiental, que continua com a Secretaria Municipal de Meio Ambiente, através do COMAM.

Entre avanços e retrocessos, o breve histórico da regulação ambiental no espaço urbano evidencia o papel do Estado que ora age como conciliador de interesses, ora busca uma pretensa objetividade como quando define critérios objetivos de licenciamento das diversas atividades na cidade. Em ambos os casos, explicita ou busca atenuar, via processos participativos, a exemplo de audiências públicas, os conflitos socioambientais desencadeados durante o processo de licenciamento. Embora não tenha sido objeto do presente artigo, a análise mais ampla que lhe serve de referência aponta para o papel central da sociedade civil, em sua relação com o Estado, como potencializadora de transformações mais abrangentes no espaço urbano, nas quais a regulação urbanística e ambiental tem um importante papel a desempenhar (LASCHEFSKI; COSTA, 2008).

A politização do discurso e das práticas ambientais, ao explicitar as contradições e (im)possiblidades do agir democrático como forma de promover mudança social e justiça sócioambiental, aponta para a necessidade de maior instrumentalização do Estado, maior diálogo deste com a sociedade civil, no sentido da integração de políticas públicas e da ampliação das formas de participação popular nos processos de planejamento e gestão urbano-ambiental. 


\title{
Environmental regulation in urban space: the trajectory of environmental licensing in the city of Belo Horizonte
}

\begin{abstract}
The article discusses some contradictions and possibilities of environmental law as a regulatory urban activity mechanism. It analyses the environmental regulation process in force in Belo Horizonte during a period of ten years. Emphasis is given to the changes associated to definitions of environmental impact of urban activities and the conditions in which permits are given to them. Finally a spatial analysis is presented in order to discuss some relationships between the characteristics of the licensed activities and their location within urban space.
\end{abstract}

Key words: Environmental regulation; Urban space; Public policy; Legislation; Environmental permit.

\section{Referências}

ACSELRAD, H. (Org.). A duração das cidades: sustentabilidade e risco nas políticas urbanas. Rui de Janeiro: DP\&A, 2001.

ACSELRAD, H. Justiça ambiental - novas articulações entre meio ambiente e democracia. In: ACSELRAD, H. (Org.). Conflitos ambientais no Brasil. Rio de Janeiro: Relume Dumará: Fundação Heinrich Böll, 2004.

ARAÚJO, R.P.Z. Contradições e possibilidades da regulação ambiental no espaço urbano. 2009. 221 f. Tese (Doutorado em Geografia) - Instituto de Geociências, Universidade Federal de Minas Gerais, Belo Horizonte.

BASSUL, J.R. Estatuto da Cidade: quem ganhou? Quem perdeu? Brasília: Senado Federal, Sub secretaria de Edições Técnicas, 2005.

CARNEIRO, J.A. Oligarquização da "política ambiental" mineira. In: ZHOURI, A.; LASCHEFSKI, K.; PEREIRA, D.B. A insustentável leveza da política ambiental: desenvolvimento e conflitos sócio-ambientais. Belo Horizonte: Autêntica, 2005.

CAVAlCANTI, C. (Org.). Desenvolvimento e natureza: estudos para uma sociedade sustentável. São Paulo: Cortez, 1995.

COSTA, H.S.M. Desenvolvimento urbano sustentável: uma contradição de termos? Revista Brasileira de Estudos Urbanos e Regionais, Recife, n. 2, p. 55-71, 2000. 
COSTA H.S.M. A trajetória da temática ambiental no planejamento urbano no Brasil: o encontro de racionalidades distintas. In: COSTA G.M.; MENDONÇA, J.G (Org.). Planejamento Urbano no Brasil trajetória, avanços e perspectivas. Belo Horizonte: C/Arte, 2008a.

COSTA, H.S.M. Meio ambiente e desenvolvimento: um convite à leitura. In: HISSA, C.E.V. (Org.). Saberes ambientais. Desafios para o conhecimento disciplinar. Belo Horizonte: Editora UFMG, 2008b. p. 79-107.

COSTA, H.S.M. Mercado imobiliário, Estado e natureza na produção do espaço metropolitano. In: COSTA, H.S.M. et al. (Org.) Novas periferias metropolitanas. Belo Horizonte: C/Arte, 2006.

COSTA, H.S.M., ARAUJO, R.P.Z., CAMPANTE, A.L.G. A dimensão ambiental nos Planos Diretores de municípios brasileiros: um olhar panorâmico sobre a experiência recente. In: SANTOS Jr., O.A.; MONTANDON, D.T. (Org.). Os Planos Diretores Municipais pós Estatuto da Cidade: balanço crítico e perspectivas. Rio de Janeiro: Letra Capital, Observatório das Metrópoles/IPPUR/UFRJ, 2011.

FREITAS, J.M.F. Perspectivas do planejamento urbano contemporâneo: reflexões a partir do caso de Belo Horizonte. 1996. 212 f. Dissertação (Mestrado em Geografia) Instituto de Geociências, Universidade Federal de Minas Gerais, Belo Horizonte.

FERNANDES, E. Law, politics and environmental protection in Brazil. Journal of Environmental Law. London: Oxford University Press, v. 4, n. 1, p. 41-56, 1992.

HARVEY, D. Justice, nature and the geography of difference. Blackwell, 1996.

LASCHEFSKI, K.; COSTA, H.S.M. Segregação social como externalização de conflitos ambientais: a elitização do meio ambiente na APA-Sul, região metropolitana de Belo Horizonte. Ambiente \& Sociedade. Campinas, v. 11, n. 2, p. 307-322, jul./dez. 2008 .

MOL, N.A. Leis e Urbes - um estudo do impacto da Lei de Parcelamento, Ocupação e Uso do Solo de Belo Horizonte. 2004. 142 f. Dissertação (Mestrado em Geografia) - Instituto de Geociências, Universidade Federal de Minas Gerais, Belo Horizonte.

PEET, R.; WATTS, M. (Ed.) Liberation ecologies. Environment, development, social movements. London \& New York: Routledge, 1996.

PRESTES, V. B. A necessidade de compatibilização das licenças ambiental e urbanística no processo de municipalização do licenciamento ambiental. Revista de Direito Ambiental, São Paulo, v. 37, p. 5-28, 2005. 
TEIXEIRA, S.M. Participação popular na gestão de políticas públicas ambientais: o caso do COMAM - Conselho Municipal do Meio Ambiente de Belo Horizonte. 2004. 170 f. Dissertação (Mestrado em Sociologia). Universidade Federal de Minas Gerais, Faculdade Filosofia e Ciências Humanas, Belo Horizonte.

VIOLA, E.; LEIS, H. A evolução das políticas ambientais no Brasil, 1971-1991. In: HOGAN, D.; VIEIRA, P. (Org.). Dilemas sócio-ambientais e desenvolvimento sustentável. Campinas: Editora da Unicamp, 1992.

ZHOURI, A.; LASCHEFSKI, K.; PAIVA, A. Uma sociologia do licenciamento ambiental: o caso das hidrelétricas em Minas Gerais. In: ZHOURI, A.; LASCHEFSKI, K.; PEREIRA, D. (Org.). A insustentável leveza da política ambiental: desenvolvimento e conflitos socioambientais. Belo Horizonte: Autêntica, 2005.

Recebido em julho de 2011. Aprovado em novembro de 2011. 